Conteh L, Kurowski C, et al. Improving the health of the global poor. Science 2002;295:2036-9.

3. Easterlin RA. How beneficent is the market? A look at the modern history of mortality. Eur Rev Econ Hist 1999;3(3):257-94.

4. Deaton A. Health, inequality, and economic development. Paper no. WG1:3 of CMH Working Paper Series. [place unknown]: Commission on Macroeconomics and Health; 2001 May. Available: www.cmhealth.org/docs/wg1_paper3.pdf (accessed 2004 Sep 8)

5. Measham AR, Rao KD, Jamison DT, Wang J, Singh A. The performance of India and Indian states in reducing infant mortality and fertility, 1975-1990. Econ Polit Wkly 1999;34(22):1359-67.

6. Jha P. Avoidable mortality in India: past progres and future prospects. Natl Med 7 India 2002;15 (Suppl 1):32-6.

DOI:10.1503/cmaj.1041238

\section{Seeking clarification of osteoporosis guidelines}

$\mathrm{T}$ he recent statement of the Canadian Task Force on Preventive Health Care regarding prevention of osteoporosis and osteoporotic fractures in postmenopausal women ${ }^{1}$ contains some confusing information. One example is the statement that "Although there is no direct evidence that screening reduces fractures, there is good evidence that screening is effective in identifying postmenopausal women with low bone mineral density and that treating osteoporosis can reduce the risk of fractures in this population." This wording appears to have been chosen to obfuscate the meaning, since low bone mineral density, particularly in the younger population, does not strongly correlate with fracture risk or osteoporosis. ${ }^{2,3}$

Other parts of the recommendation statement do not appear particularly practical. For example, the algorithm shown in Fig. 1 of the article ${ }^{1}$ suggests that all women 65 years of age or older should undergo repeat dual-energy $\mathrm{x}$ ray absorptiometry (DEXA) every 1 to 2 years, regardless of the result of initial DEXA (even if that result is normal). Admittedly, this agrees with the guidelines of the US Preventive Services Task Force ${ }^{4}$ and the Osteoporosis Society of Canada, ${ }^{2}$ but what does it mean for those of us providing primary care? Should we in fact send all of our female patients over age 65 , including those in rest homes, for DEXA screening? Would it not be adequate to suggest to women in this age group that they try to exercise regularly and take adequate amounts of vitamin D and calcium?

Also of great concern are the potential medicolegal implications if clinicians do not follow guidelines developed by authoritative bodies such as the Task Force.

Do the CMA7 editors accept guidelines and protocols produced by distinguished Canadian associations (often sponsored by drug companies) without the benefit of peer review or editing?

\section{John Sehmer}

Clinical Assistant Professor

University of British Columbia

Vancouver, BC

\section{References}

1. Cheung AM, Feig DS, Kapral M, Diaz-Granados, Dodin S and The Canadian Task Force on Preventive Health Care. Prevention of osteoporosis and osteoporotic fractures in postmenopausal women: recommendation statement from the Canadian Task Force on Preventive Health Care. CMAf 2004;170(11):1665-7.

2. Brown JP, Josse RG, for the Scientific Advisory Council of the Osteoporosis Society of Canada. 2002 clinical practice guidelines for the diagnosis and management of osteoporosis in Canada. CMA7 2002:167(10 Suppl):S1-34.

3. Moynihan R, Heath I, Henry D. Selling sickness: the pharmaceutical industry and disease mongering [editorial]. BM7 2002;324:886-91.

4. US Preventive Services Task Force. Screening for osteoporosis in postmenopausal women: recommendations and rationale. Ann Intern Med 2002;137:526-8

Competing interests: None declared.

DOI:10.1503/cmaj.1040991

$\mathrm{T}$ he recommendation statement from the Canadian Task Force on Preventive Health Care about preventing osteoporosis and osteoporotic fractures in postmenopausal women ${ }^{1}$ mentions oral pamidronate as a second-line drug choice. However, to the best of my knowledge, oral pamidronate is not available in Canada.

\section{Mario L. de Lemos}

British Columbia Cancer Agency

Vancouver, BC

\section{Reference}

1. Cheung AM, Feig DS, Kapral M, Diaz-Granados N, Dodin S and The Canadian Task Force on Preventive Health Care. Prevention of osteo- porosis and osteoporotic fractures in postmenopausal women: recommendation statement from the Canadian Task Force on Preventive Health Care. CMA7 2004;170(11):1665-7.

Competing interests: None declared.

DOI:10.1503/cmaj.1040953

\section{[The lead author and the chair of the Task Force respond:]}

7 he recent recommendation statement concerning the prevention of osteoporosis and osteoporotic fractures in postmenopausal women ${ }^{1}$ was developed after a detailed process of identifying the appropriate analytic framework, systematically reviewing the literature, discussing the evidence at multiple Task Force meetings and subjecting the statement to 2 levels of peer review (internal peer review within the Task Force and external peer review organized by the Task Force).

On the basis of our analytic framework and the evidence available, we concluded that there is no direct evidence that screening reduces fractures. In other words, there were no acceptable randomized controlled trials that directly evaluated routine screening linked to treatment compared with usual care. However, there is evidence that screening is effective in identifying postmenopausal women with osteoporosis. There is also evidence that treating osteoporosis can reduce the risk of fractures in postmenopausal women. Because the evidence that supports fracture reduction through screening is therefore indirect, our overall recommendation was grade $\mathrm{B}$, rather than grade $\mathrm{A}$. Currently, there is much controversy as to what the treatment threshold should be. Most experts agree that postmenopausal women with osteoporosis ( $T$ score at or below -2.5) should be treated with pharmacologic therapies, because there is good to fair evidence from randomized controlled trials that such treatment will reduce osteoporotic fractures in this population. Some of these trials have included women with $T$ scores between -2.0 and -2.5 .

There is a strong correlation be- 
tween low bone mineral density (BMD) and fracture risk in postmenopausal women, ${ }^{2,3}$ and the risk increases with age for a given level of BMD., 4 This predictive ability of BMD for fractures is greater than that of blood pressure for stroke and cholesterol level for cardiovascular disease. ${ }^{2}$ However, in younger postmenopausal women with low BMD, the absolute risk is low. ${ }^{4}$ Therefore, on the basis of the absolute fracture risk, we recommend BMD screening by DEXA for all postmenopausal women starting at age 65 (see Fig. 1 in our original article). If the result of the initial DEXA is normal, we recommend repeating this test in 2 years. On the same basis, we also recommend considering pharmacologic treatment for those over age 65 with $T$ scores between -2.0 to -2.5 . Those younger than 65 years of age with $T$ scores above -2.0 have a lower absolute risk of fracture and therefore the corresponding number needed to treat to prevent one fracture is higher.

In our statement, ${ }^{1}$ we were explicit that these recommendations do not apply to those in nursing homes, because we limited our systematic review to the community-dwelling population. We did review compounds that were not available in Canada at the time of our submission for publication but for which published evidence was available (e.g., teriparatide and oral pamidronate), as they may become available here sometime in the future. Current evidence suggests that pharmacologic therapies can further reduce fractures in osteoporotic postmenopausal women who are receiving adequate amounts of vitamin D and calcium. Although we recommend regular exercise because it can maintain BMD and reduce falls, no good evidence exists for fracture reduction with regular exercise in this population.

These evidence-based clinical guidelines are meant to guide physicians in discussions with their postmenopausal patients, as each individual woman may have unique risks and preferences. The guidelines need to be interpreted and applied sensibly. In general, clinical practice guidelines are designed to hasten the incorporation of research find- ings into routine care, but they are usually not the reference for medicolegal action. Most common law rulings in North America and the United Kingdom are based on minimum acceptable standards of clinical care, which are often derived from responsible customary practice, rather than from clinical practice guidelines. ${ }^{6,7}$

The Canadian Task Force for Preventive Health Care is funded through Health Canada and strives to provide up-to-date, unbiased guidelines for primary care physicians in Canada. No drug company was involved financially or otherwise in this recommendation statement.

\section{Angela M. Cheung}

Department of Medicine

University Health Network

University of Toronto

Toronto, Ont.

John W. Feightner

Chair, Canadian Task Force for

Preventive Health Care

Professor, Department of Family

Medicine

University of Western Ontario

London, Ont.

\section{References}

1. Cheung AM, Feig DS, Kapral M, Diaz-Granados, Dodin S and The Canadian Task Force on Preventive Health Care. Prevention of osteoporosis and osteoporotic fractures in postmenopausal women: recommendation statement from the Canadian Task Force on Preventive Health Care. CMAf 2004;170(11):1665-7.

2. Marshall D, Johneli O, Wedel H. Meta-analysis of how well measures of bone mineral density predict occurrence of osteoporotic fractures. BM7 1996;312:1254-9.

3. Hui SL, Slemenda CW, Johnston CC. Baseline measurement of bone mass predicts fracture in white women. Ann Intern Med 1989;111:355-61.

4. Hui SL, Slemenda CW, Johnston CC. Age and bone mass as predictors of fracture in a prospective study. 7 Clin Invest 1988;81:1804-9.

5. Cummings SR, Black DM, Nevitt MC, Browner WS, Cauley JA, Genant HK, et al. Appendicular bone density and age predict hip fracture in women. FAMA 1990;263:665-8.

6. Rosoff AJ. Evidence-based medicine and the law: the courts confront clinical practice guidelines. 7 Health Polit Policy Law 2001;26(2):327-68.

7. Hurwitz B. Legal and political considerations of clinical practice guidelines. BMF 1999;318:661-4.

Competing interests: Angela Cheung has received honoraria to participate in CME events partly or fully supported by Eli Lilly, Merck, Proctor \& Gamble, Aventis and Novartis; these companies have also contributed unrestricted educational grants in support of Toronto City-wide Osteoporosis Rounds, which Dr. Cheung chairs.

DOI:10.1503/cmaj.1041404

\section{Mapping malaria}

ongratulations to Kathryn Suh and $\checkmark$ colleagues $^{1}$ for their recent comprehensive review of malaria. I have 2 corrections for their Fig. 1, the map showing global distribution of malaria. First, malaria is not endemic to Uruguay. Second, in Paraguay, malaria is in fact sensitive (not resistant) to chloroquine.

\section{Tomás A. Orduna \\ Tropical Medicine \\ Hospital de Infecciosas F.J. Muñiz \\ Buenos Aires, Argentina}

\section{Reference \\ 1. Suh KN, Kain KC, Keystone JS. Malaria. CMAf 2004;170(11):1693-702.}

Competing interests: None declared.

DOI:10.1503/cmaj.1041374

[The authors respond:]

W e thank Tomás Orduna for bringing to our attention some inaccuracies in the map illustrating the global distribution of malaria, which appeared in our review article on this disease. ${ }^{1} \mathrm{He}$ is correct in pointing out that there is no risk of malaria in Uruguay and that only chloroquinesensitive malaria is present in Paraguay.

As noted in the original figure caption, the map was intended as a visual aid only and was not meant to provide definitive recommendations regarding malaria risk and prophylaxis. Furthermore, malaria risk may vary within a given country, and hence not all travellers to that country will necessarily require malaria prophylaxis. Readers are therefore referred to additional travel medicine resources, such as Health Canada, the US Centers for Disease Control and Prevention and the World Health Organization (as suggested in the original figure caption and listed at the end of our article ${ }^{1}$ ), for current recommendations regarding country-specific malaria risks and recommended prophlyaxis.

Our Fig. 1 was published courtesy of Health Canada's Committee to Advise on Tropical Medicine and Travel 